$$
\begin{aligned}
& 1 N-08 \\
& 040915
\end{aligned}
$$

NASA Technical Memorandum 107466

\title{
Speed Sensorless Induction Motor Drives for Electrical Actuators: Schemes, Trends and Tradeoffs
}

Malik E. Elbuluk

University of Akron

Akron, Ohio

and

M. David Kankam

Lewis Research Center

Cleveland, Ohio

Prepared for the

National Aerospace and Electronics Conference

cosponsored by IEEE, Wright-Patterson AFB, and AESS

Dayton, Ohio, July 14-18, 1997

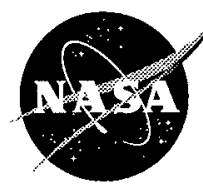

National Aeronautics and

Space Administration 


\section{SPEED SENSORLESS INDUCTION MOTOR DRIVES FOR ELECTRICAL ACTUATORS : SCHEMES, TRENDS AND TRADEOFFS}

\author{
Malik E. Elbuluk \\ Electrical Engineering Department \\ University of Akron \\ Akron, Ohio 44325-3904
}

\author{
M. David Kankam \\ Power and On-Board Propulsion Division \\ NASA Lewis Research Center, MS 301-5 \\ Cleveland, Ohio 44135
}

Key Words: Aerospace, Electrical Actuators, Speed Sensorless Induction Motor Drives, Observer, Model Reference Adaptive System, Aircraft Launch Vehicles.

\begin{abstract}
For a decade, induction motor drive-based electrical actuators have been under investigation as potential replacement for the conventional hydraulic and pneumatic actuators in aircraft. Advantages of electric actuator include lower weight and size, reduced maintenance and operating costs, improved safety due to the elimination of hazardous fluids and high pressure hydraulic and pneumatic actuators, and increased efficiency.

Recently, the emphasis of research on induction motor drives has been on sensorless vector control which eliminates flux and speed sensors mounted on the motor. Also, the development of effective speed and flux estimators has allowed good rotor flux-oriented (RFO) performance at all speeds except those close to zero. Sensorless control has improved the motor performance, compared to the Volts/Hertz (or constant flux) controls.

This report evaluates documented schemes for speed sensorless drives, and discusses the trends and tradeoffs involved in selecting a particular scheme. These schemes combine the attributes of the direct and indirect field-oriented control (FOC) or use model adaptive reference systems (MRAS) with a speed-dependent current model for flux estimation which tracks the voltage model-based flux estimator.

Many factors are important in comparing the effectiveness of a speed sensorless scheme. Among them are the wide speed range capability, motor parameter insensitivity and noise reduction. Although a number of schemes have been proposed for solving the speed estimation, zero-speed FOC with robustness against parameter variations still remains an area of research for speed sensorless control.
\end{abstract}

\section{Introduction}

The induction motor has been the workhorse of industry for many years. In particular, the squirrel cage motor is one of the most important ac machines because of its low cost, high reliability, low inertia and high transient torque capacity. Significant advances in power electronics have permitted the implementation of sophisticated methods for control of induction motors, using FOC which allows decoupling and separate control of the torque and flux components of the stator currents. Two types of field-oriented control are available. One is the direct field-oriented control which regulates the rotor flux using direct measurements of rotor flux magnitude and position. The other is the indirect field-orientation in which the rotor flux is regulated by the slip frequency, the stator currents and the rotor speed.

There are a number of trends and tradeoffs involved in implementing the different forms of field-oriented control. First, most of the field orientation methods require precise estimation of either the rotor position or speed. This implies the need for speed sensors such as shaft-mounted tacho-generators, resolvers or digital shaft encoders. The speed sensors lower the system reliability and, also, require special attention to measurement noise. Second, the direct field-oriented scheme requires the rotor flux which is measured using Hall effect sensors or search coils. The Hall effect sensors degrade the performance and reliability of the drive system. Third, the implementation of direct field orientation uses an open-loop integration of the machine voltage to estimate the flux, which gives problems at low speeds. Finally, although the indirect field-oriented control scheme is simple 
and preferred, its performance is highly dependent on an accurate knowledge of the machine parameters.

Research in induction motor drives, for the past fifteen years, has focused on improving the different field- oriented schemes to remedy the above problems. In particular, much work has been done in decreasing the sensitivity of the control system to the motor parameter estimates, and estimating, rather than measuring, the rotor flux or speed from the terminal voltages and currents. This eliminates the flux or speed sensor, thereby achieving sensorless control. The estimators are, also, known as observers. Another control scheme, known as direct self control (DSC) or direct torque control (DTC), requires only stator parameters, and has been developed as an alternative sensor-less drive.

Fig 1 shows a general sensorless drive. Signals representing the terminal voltages and currents are fed to observers for estimating the rotor flux magnitude, angle and speed. The estimated quantities are compared with their respective command values. The errors are fed into the controllers which feed the power electronic converters.

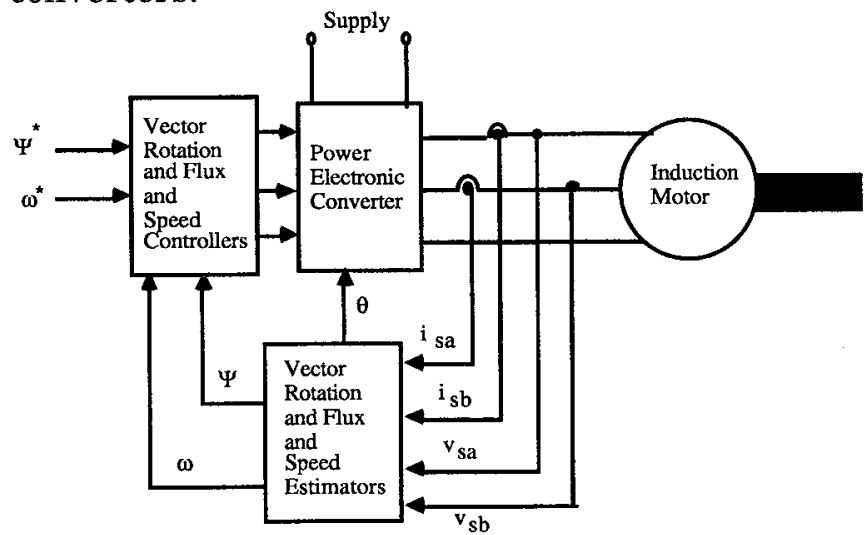

Fig. 1 Speed Sensorless FOC System

A number of developed approaches for flux and speed observers are documented in the literature. In the past two years the University of Akron, and the Power and On-Board Propulsion Technology Division at NASA Lewis Research Center have been investigating and developing an induction motor drive system for aerospace applications. An example of such applications is replacing hydraulic actuators in launch vehicles and aircraft with electrical actuators [43]-[44]. The motor drive system implemented uses a direct FOC. A rotor flux observer has been developed to overcome problems encountered in previous flux observers. However, the observer requires the motor rotor speed and a shaft encoder for speed sensing.

Research reported here aimed at eliminating the speed sensor. This required a survey on and evaluation of more than thirty technical papers on sensorless techniques for induction motor drives. This report summarizes of our findings. A follow-up of the study is to adopt either one of the searched techniques, or combine the attributes of many techniques to obtain a better sensorless drive.

\section{Essentials of Observer Theory}

Most systems can be modeled by a statespace description of the form [1]:

$$
\begin{gathered}
\frac{d x(t)}{d t}=A x(t)+B u(t)+G d(t) \\
y(t)=C x(t)+H d(t)
\end{gathered}
$$

where :

$\mathbf{x}(t)$ is a state vector, $\mathbf{u}(\mathrm{t})$ is a vector of known inputs, $\mathbf{d}(\mathrm{t})$ is a vector of unknown inputs, $\mathbf{y}(t)$ is a vector of outputs and $\mathbf{A}, \mathbf{B}, \mathbf{C}, \mathbf{G} \& \mathbf{H}$ are matrices of appropriate dimensions. The observer theory aims at providing real-time estimate of the state $\mathbf{x}(\mathrm{t})$ using only $\mathbf{u}(\mathrm{t})$ and $\mathbf{y}(\mathrm{t})$. A state equation representing the estimated state vector, $\widehat{\mathbf{x}}$, is

$\frac{d \widehat{x}(t)}{d t}=\mathbf{A} \widehat{\mathbf{x}}(\mathrm{t})+\mathbf{B} u(t)+\mathbf{K}(\mathbf{C} \widehat{\mathbf{x}}(\mathrm{t})-\mathbf{y}(\mathrm{t}))$

where $(\mathbf{C} \widehat{\mathbf{x}}(\mathrm{t})-\mathbf{y}(\mathrm{t}))$ is known as the prediction error and $\mathrm{K}$ is known as the observer gain. The effectiveness of the observer is assessed by examining the dynamics of the estimation error

$$
e(t)=\widehat{x}(t)-x(t)
$$

the state equation of which is:

$\frac{\mathrm{de}(\mathrm{t})}{\mathrm{dt}}=(\mathbf{A}+\mathbf{K C}) \mathbf{e}(\mathrm{t})+(\mathbf{G}+\mathbf{K H}) \mathbf{d}(\mathrm{t})$

The dynamics of Equation (4) is governed by the eigenvalues of the matrix $(A+K C)$. If these eigenvalues have negative real part, then the estimate $\widehat{\mathrm{x}}$ will approach the actual $\mathrm{x}$. Fig. 2 shows a block diagram of a linear state observer.

The literature shows many approaches for manipulating the induction machine equations so as to develop observers for estimating the machine fluxes, speed or position. This report summarizes the observers used to estimate the rotor speed, or eliminate the need for it, in fieldoriented schemes. The various approaches on sensorless control are discussed in the sections that follow. 


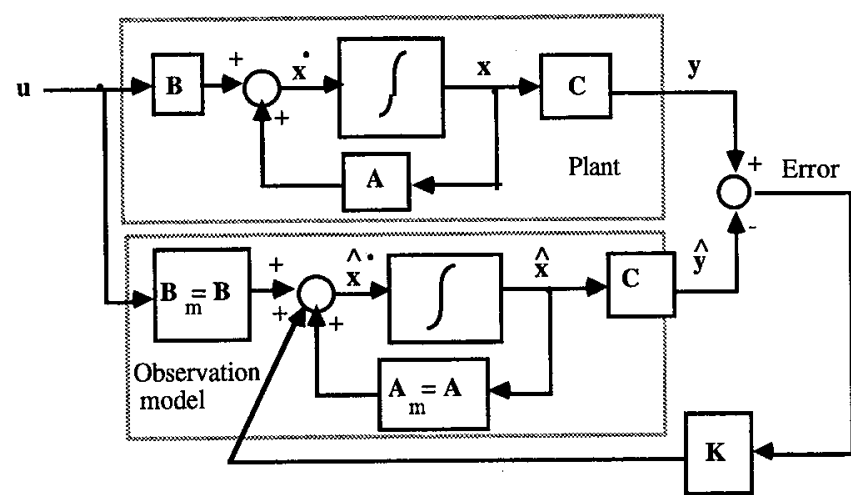

Fig. 2 Linear State Observer

\subsection{Speed Identification Schemes}

\subsection{Kalman Filter Schemes}

The Kalman filter algorithm and its extension are robust and efficient observers for linear and nonlinear systems, respectively. The observers use knowledge about the system dynamics and statistical properties of the system, and measurement noise sources to produce an optimal state estimation. A continuous time model is used in case of the Kalman filter, whereas the extended Kalman filter requires a discrete statespace model. A major advantage of the Kalman filtering approach is its fault tolerance which permits system parameter drifts. Therefore, exact models are not required.

The application of full- and reduced-order versions of Kalman and Extended-Kalman filters to speed estimation in induction motor and drives has been investigated [11],[12] and [31]. Fig. 3 shows a typical structure of a Kalman filtering approach.

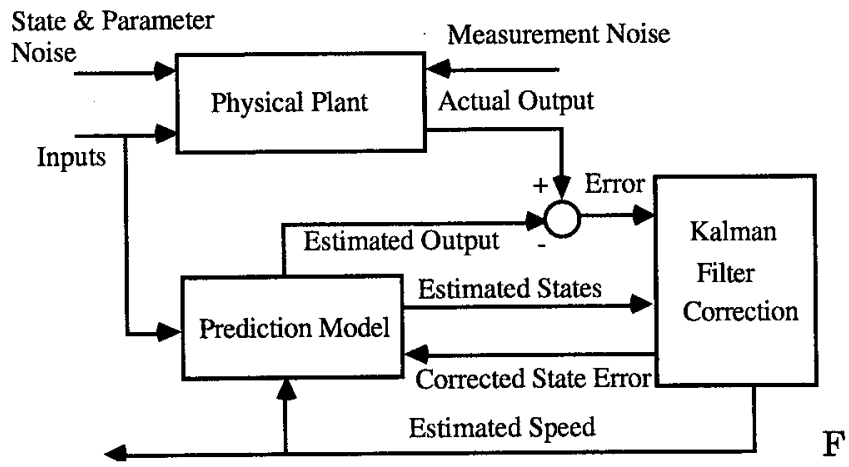

ig. 3 Kalman Filter Structure

The inputs to the plant are fed into a prediction model. The output of the plant is compared with the output from the model, and the resulting error is fed into a correction Kalman gain stage to reduce the error in the estimated states from the prediction model.
Different models of the induction machine for use with Kalman filter have been proposed in Ref. [31]. The results indicate that the operating range of the sensorless drive is not reduced for static, dynamic or field weakening operation.

In Refs. [11] and [12] the full- and reduced-order models Extended Kalman filter are used for rotor flux and speed estimation, using direct field orientation. The use of reduced-order model has the advantage of saving computation time, in comparison with the full-order extended Kalman filter. The developments in the real time computational speed of digital signal processing chips make the Kalman filter a powerful approach to sensorless vector control. However, the robustness and sensitivity to parameter variation needs further study [11].

\subsection{Model Reference Adaptive Schemes}

Adaptive control has emerged as a potential solution for implementing high performance control systems, especially when dynamic characteristics of a plant are poorly known, or have large and unpredictable variations.

Model reference adaptive system (MRAS) achieves robust and high performance. The main innovation of MRAS is the presence of a reference model which specifies the desired performance. The output of the reference model is compared with an adjustable observer-based model. The error is fed into an adaptation mechanism which is designed to assure the stability of the MRAS.

A number of MRAS-based speed sensorless schemes have been described in the literature for field-oriented induction motor drives [5], [8], [9], [13], [15]-[17], [20], [23], [27]-[30]. Fig. 4 shows a typical MRAS speed estimator. The output of the reference model does not have an explicit dependence on the motor speed. The output of the adjustable model has a speeddependence. For example, the inputs to both the reference and adjustable models can be stator voltages, and the outputs are fluxes or back emf. The difference between the outputs is fed into a speed adaptive scheme the output of which is the estimated speed used to correct the adjustable model.

Many simplified motor models have been devised to estimate the speed of the induction motor, using MRAS schemes. The voltage model, shown in Fig. 5, for rotor flux estimation is commonly used as a reference model, since it does not depend on the rotor speed [36]-[37]. The current model, shown in Fig. 6, is used for the adjustable model, since it is speed-dependent [36][37]. The implementation of the two models in different reference frames affects the complexity and robustness of the MRAS scheme [5]. Recently, a number of closed-loop observers that 
combine the best attributes of the voltage and current models with MRAS and other sensorless approaches have been developed. This has resulted in increased research in direct field orientation, as compared to the standard indirect field orientation employed in induction motor drives [36]-[38].

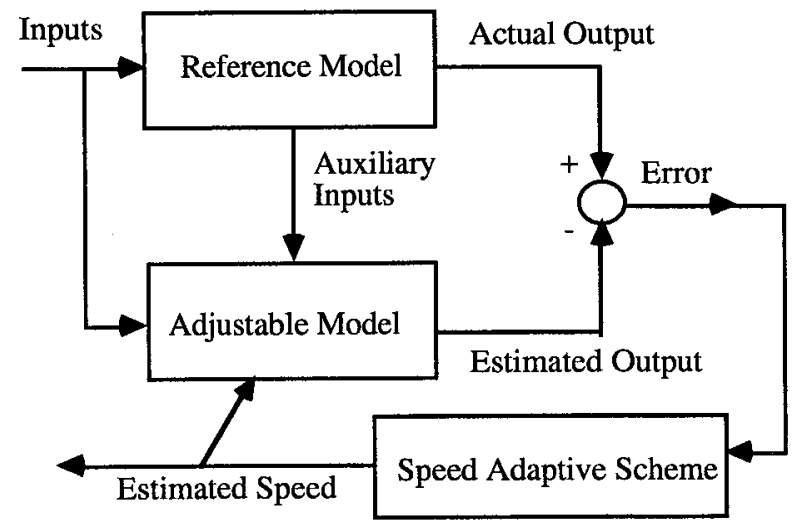

Fig. 4 Typical MRAS For Speed Estimation.

The speed adaptive algorithm used affects the stability and dynamic performance of the closed-loop MRAS. In many cases, a proportionalintegral (PI) controller is found to be satisfactory for the adaptive scheme.

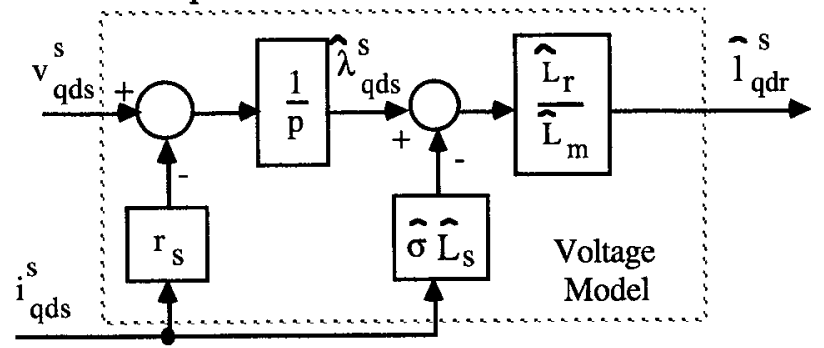

Fig. 5 Voltage Model for Rotor Flux Estimation.

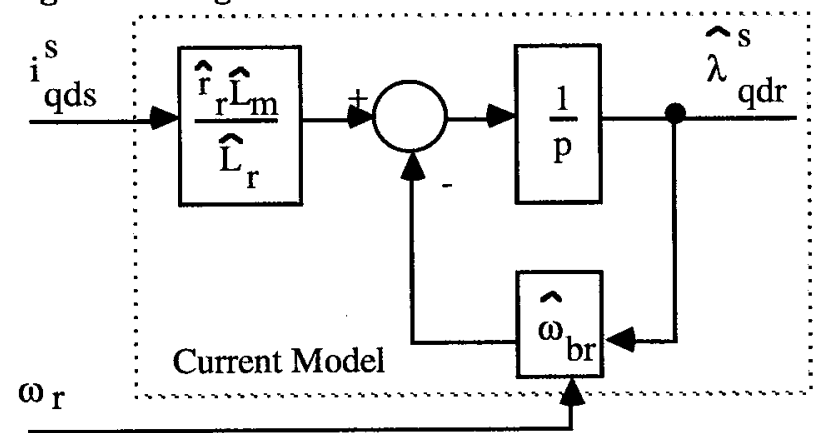

Fig. 6 Current Model for Rotor Flux Estimation.

\subsection{High Frequency Signal Schemes}

Recently, new rotor position and speed estimations have been developed, using high frequency measurements, based on machine saliencies, rotor slotting and irregularities [24][25]. Proper signal processing and filtering of the resulting high frequency stator current are used to detect the induced saliencies present in the stator model of the induction motor. High frequency signals are injected into the stator terminals using the same inverter that supplies the fundamental excitation. Such detection provides continuous estimate of the position and magnitude of flux [18], [21], [24]-[25].

The above approaches have been shown to have the potential for wide-speed and parameterinsensitive sensorless control, particularly during low speed operation, including zero speed. Increased research is expected in this area.

\subsection{Direct Self Control Schemes}

A number of field-orientation methods have been developed. These methods use only measured stator voltages and currents to implement a sensorless control [4], [31]-[33]. The most promising scheme is the direct self control (DSC), also known as direct torque control (DTC), shown in Fig. 7. It is a variation of field oriented control but uses only the stator resistance in its calculations. This makes the DSC less sensitive to parameter changes [4]. Such a control is. In DSC, the flux position and the errors in the torque and flux are directly used to choose the inverter switching state.

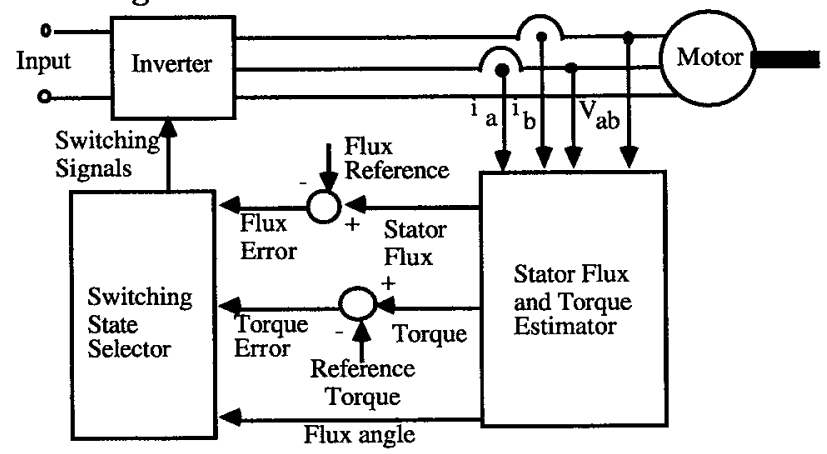

Fig. 7. Direct Self Controller.

Due to estimation of flux based on integration of a voltage signal, DSC has limitations at low speeds. Also, frequency and temperature variations tend to cause corresponding change in the actual motor resistance, thereby creating an error in the estimate of the stator flux. Tuning the stator resistance used in the controller to track the above changes in the actual motor resistance will improve the DSC scheme, and increase its potential as a simple sensorless control.

\subsection{Intelligent Control Techniques}

Neural Networks (NNs) and Fuzzy Logic are gaining potential as estimators and controllers for many industrial applications, due to the fact that they present better properties than the conventional controllers. 
NNs have learning capability to approximate very complicated nonlinear functions, and therefore considered as universal approximation. Also, they have adaptive capability which makes them very powerful in applications where the dynamics of a plant are time-variant or where the model of the system is partially known. The main advantage of $\mathrm{NNs}$ is their inherent fault tolerance. Fig. 8 shows a typical NN and a general architecture of NN control of a plant. Fig. 8 shows a typical neuron, Artificial Neural Network (ANN) structure and NN control of a plant (Fig. 8c).

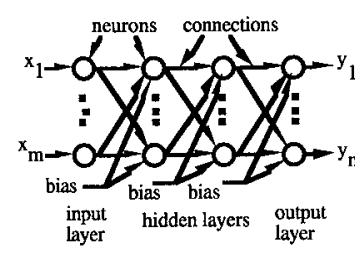

(a) Feedforward ANN structure.

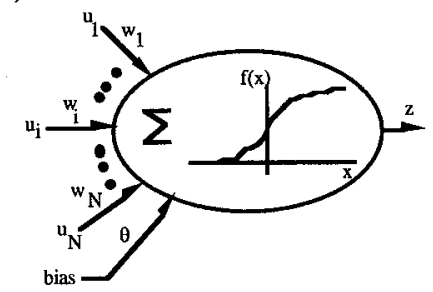

(b) Single neuron structure

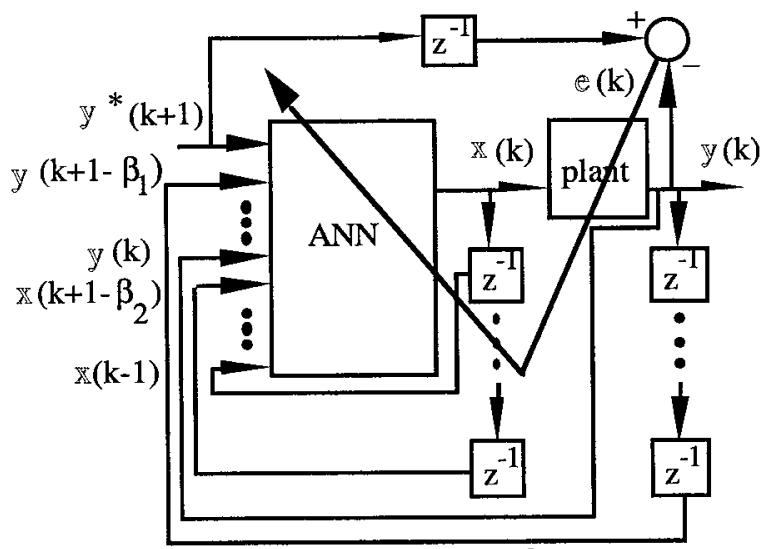

(c) NN control of a plant

Fig. 8 NN Structure and Control System

A fuzzy controller converts a set of linguistic rules, based on expert knowledge, into an automatic control strategy. Such controllers have been found to be superior to conventional controllers, especially when information being processed is inexact or uncertain. Fig. 9 shows a typical fuzzy control system.

In Ref. [34], neural networks are used to estimate feedback signals required for vector control of induction motor drives. In Refs. [39]-[42], NN and fuzzy logic have been used to implement and tune the DSC discussed in Section 3.4. The results obtained showed improvement over the conventional DSC, especially at low speeds.

The drawbacks of NN and fuzzy logic include requirement of much training or knowledge base to understand the model of a plant or a process. The training algorithm used has an effect on issues such as learning speed, stability and weight convergence. These issues remain as areas of research and comparison of many training algorithms.

\subsection{Conclusions}

A summary of the literature on schemes for speed sensorless drives has been given. The trends and tradeoffs of the different speed sensorless schemes are discussed. Further research areas needed in each scheme are noted.

Although a number of schemes have been proposed for solving the speed estimation, many factors remain important in comparing their effectiveness. Among these factors are the wide speed range capability, motor parameter insensitivity and noise reduction. In particular, zero-speed vector control with robustness against parameter variations yet remains an area of research for speed sensorless control.

Future work on induction motor drivebased electrical actuators should develop a speed sensorless scheme that will investigate and effectively incorporate the above factors. Such a sensorless drive is expected to yield more reliable, high performance and cost-effective electrical actuators which will benefit thrust vector control of launch vehicles and, also, aircraft upgrade.

\section{Acknowledgments}

The authors are grateful for the funding received from the Power and On-Board Propulsion Technology Division at NASA Lewis Research Center in Cleveland, $\mathrm{OH}$. Also, the authors thank Mr. James L. Dolce and Mrs. Barbara H. Kenny of Electrical System Development Branch for their constructive review of the report.

\section{References}

[1] G. Verghese and S. Sanders, "Observers for Flux Estimation in Induction Machines," IEEE Trans. on Industrial Electronics, Vol. 35 , No. 1 , pp. 85-94.

[2] A. Fratta, A. Vagati, and Franco Villata, "Vector Control of Induction Motors without Shaft Transducers," Proceedings of the IEEE 1988 Power Electronics Specialists Conference (PESC), pp. 839-846.

[3] H. Nakano, and I. Takahashi, "Sensorless Field Oriented Control of Induction Motor Using an Instantaneous Slip Frequency Estimation Method," IEEE PESC 1988, pp. 847-854.

[4] U. Baader, M. Depenbrock, and G. Gierse, "Direct Self Control of Inverter-Fed Induction Machines: A Basais for Speed Control Without A Speed Measurement," IEEE 1989 Industry Application Society Conference, pp. 486-492. 
[5] C. Schauder, "Adaptive Speed Identification For Vector Control of Induction Motors Without Rotational Transducers," IEEE 1989 Industry Application Society Conference, pp. 493-499.

[6] T. Ohtani, N. Takada, and K. Tanaka, "Vector Control of Induction Motor without Shaft Encoder," IEEE 1989 Industry Application. Society Meeting, pp. 500-507.

[7] M. Ve'lez-Reyes, K. Minami \& G.C. Verghese," Recursive Speed and Parameter Estimation for Induction Machines," IEEE 1989 Industry Application Society Conference, pp. 607-611.

[8] H. Kubota, K. Matsuse \& T. Nakano, "DSPbased Speed Adaptive Flux Observer of Induction Motor," IEEE 1991 Industry Application Society Conference, pp. 380-384.

[9] H. Tajima and Yoichi Hori, "Speed Sensorless Field Orientation Control of the Induction Machine," IEEE 1991 Industry Application Society Conference, pp. 385-391

[10] P. Nadam, G. Cummings and W. Dunford, "Experimental Study of an Observer-based Shaft Sensorless Variable Speed Drive," IEEE 1989 Industry Application Society Meeting (IAS'89), pp. 392-396.

[11] Y. Kim, S. Sul, M. Park, "Speed Sensorless Vector Control of Induction Motor Using Extended Kalman Filter," IEEE Trans. on Industry Applications, Vol. 30, No. 5, Sep/Oct. 1994, pp. 1225-1233.

[12] Y. S. Kim, S. U. Kim, and L. W. Yang, "Implementation of A Speed Sensorless Vector Control of Induction Motor By Reduced-Order Extended Kalman Filter," IEEE 1995 Applied Power Electronics Conference (APEC'95), pp. 197-203.

[13] T. Kanmachi \& Isao Takahashi, "Sensorless Speed Control of An Induction Motor with No Influence of Secondary Resistance Variation," IEEE 1993 Industry Application Society Conference, pp. 408-413.

[14] L. B-Brahim, and A. Kawamura, "A Fully Digitized Field Oriented-Controlled Induction Motor Drive Using Only Current Sensors," IEEE Trans. on Industrial Electronics, Vol. 39, No. 3, Jun. 1992, pp. 241-249.
[15] H. Kubota \& K. Matsuse, "Robust Field Orientated Induction Motor Drives based on Disturbance torque Estimation without Rotational Transducers," IEEE 1993 Indust. Application Conference, pp. 558-562.

[16] H. Tajiama and Y. Hori, "Speed Sensor-less Field-Orientation Control of the Induction Machine," IEEE Trans. on Industry Applications, Vol. 29, No. 1, 1993, pp. 175180.

[17] H. Kubota, and K. Matsuse, "Speed Sensorless Field-Oriented Control of Induction Motor with rotor resistance Adaptation," IEEE Trans. on Industry Applications, Vol. 30, No. 5, 1994, pp. 12191223.

[18] P.L. Jansen and R.D. Lorenz, "Transducerless Position and Velocity Estimation in Induction and Salient AC Machines," IEEE 1994 Industry Application Society Conference, pp. 488-495.

[19] R. Lorenz, and K. Patten, "High Resolution Velocity Estimation for all Digital, AC Servo Drives," IEEE 1988 Industry Appl. Society Meeting, pp. 363-368.

[20] F. Z. Peng, and T. Fukao, "Robust Speed Identification for Speed Sensor-less Vector Control of Induction Motors," IEEE Trans. on Industry Applications, Vol. 30, No. 5, 1994, pp. 1234-1240.

[21] S. Yong, J.W. Choi \& S. K. Sul, "Sensor-less Vector Control of Induction Machine Using High Frequency Current Injection," IEEE 1994 Industry Application Society Conference, pp. 503-508.

[22] B. Bose, M. Simoes, D. Crecelius, K. Rajashekara and R. Martin "Speed Sensorless Hybrid Vector Controlled Induction Motor Drive," IEEE 1995 Industry Application Society Meeting, pp. 137-143.

[23] F.Z. Peng, Tadashi Fukao and J.S. Lai, "Low Speed Performance of Robust Speed Identification Using Instantaneous Reactive Power for Tacho-less Control of Induction Motors," IEEE 1995 Industry Application Society Conference, pp. 509-514. 
[24] K.D. Hurst, T.G. Habetler, G. Griva, F. Profoumo, "Speed Sensor-less Field-oriented Control of Induction Motor Using Current Harmonic Spectral Estimation," IEEE 1995 Industry Application Society Conference, pp. 601-607.

[25] P. Jansen, R. Lorentz, "Transducerless Field Orientation Concepts Employing SaturationInduced Saliencies in Induction Machines," IEEE 1995 Industry Application Society Meeting, pp. 174-181.

[26] J.P. Rognon, D. Roye, and D. S. Zhu, "A Simple Speed Observer for Digitally Controlled Motor Drives at Low Speeds," IEEE 1988 Industry Application Society Conference, pp. 369-374.

[27] C. Bonanno, L. Zhen, L. Xu, "Direct Field Oriented Induction Machine Drive with Robust Flux Estimator for Position Sensorless Control," IEEE 1995 Industry Application Society Conf., pp. 166-173.

[28] L. Zhen, L. Xu, "Mutual MRAS Identification Scheme for Position Sensorless Field Orientation Control of Induction Machines," IEEE 1995 Industry Application Society Conference, pp. 159-165.

[29] R. Blasco-Gime'nez, G.M. Asher, K.J. Bradley, "Dynamic Performance Limitations for MRAS-Based Sensor-less Induction Motor Drives. Part 1: Stability Analysis for The Closed-Loop Drive," IEE Proc. on Electric Power and Applications, Vol. 143, No. 2, March 1996.

[30] R. Blasco-Gime'nez, G.M. Asher, K. J. Bradley, "Dynamic Performance Limitations for MRAS-Based Sensor-less Induction Motor Drives. Part 2: On-Line Parameter Tuning and Dynamic Performance Studies," IEE Proc. on Electric Power and Applications, Vol. 143, No. 2, March 1996.

[31] B.J. Brunsbach, G. Henneberger, and T. Klesch., "Realization of A Sensorless FieldOriented Controlled Drive of an Induction Motor with a Kalman Filter, " PCIM on Intelligent Motion, 1991, pp. 53-64.

[32] R. Jotten and G. Maeder, "Control Methods for Good Dynamic Performance Induction Motor Drives Based on Current and Voltage as Measured Quantities," IEEE Trans. on Industry Applications, Vol. 19, No. 3, May/Jun. 1983, pp. 356-362.
[33] D. Zinger, F. Profumo, T. Lipo and D. Novotny, "A Direct Field-Oriented Controller for Induction Motor Drives Using Tapped Stator Windings," IEEE Trans. on Power Electronics, Vol. 5, No. 4, Oct. 1990, pp. 446-453.

[34] M. Simoes and B. Bose, "Neural NetworkBased Estimation of Feedback Signals for a Vector-Controlled Induction Motor," Proc. of IEEE Applied Power Electronics Conference (APEC), 1994, pp. 471-479.

[35] J. Dixon, J. Rivarola, "A Wide Range Sensorless Speed Estimator Based on Rotor Irregularities for Induction Motors," IEEE Applied Power Electronics Conference (APEC), 1995, pp. 204-210.

[36] P. L. Jansen and R.D. Lorenz, "A Physically Insightful Approach to the Design and Accuracy Assessment of Flux Observers for Field Oriented Induction Machine Drives", IEEE Trans. on Industry Applications, Vol. 30, No. 1, Jan/Feb.. 1994, pp. 101-109.

[37] N. Langovsky, M. Elbuluk and M. D. Kankam "Nonlinear Flux Observer with OnLine Parameter Tuning for Wide Speed Range of Induction Motors",Proc IEEE-IAS Annual Meeting, October 1995.

[38] M. Elbuluk, N. Langovsky and M. D. Kankam, "Design and Implementation of A Closed-Loop Observer and AdaptiveController for Induction Motor Drives,' Proceedings of the IEEE 1996 Industry Application Society Conference (IAS'96).

[39] S. Mir, D. Zinger, M. Elbuluk "Fuzzy Logic Control of Inverter-Fed Induction Machines", Proceedings of The IEEE Industry Application 27th Annual Meeting, Houston, Texas, October 1992, pp. 464-471.

[40] S. Mir, D. Zinger, M. Elbuluk " Fuzzy Implementation of Direct Self Control of Inverter-Fed Induction Machines", Proceedings of The IEEE Industry Application Society 28th Annual Meeting (IAS'93), Toronto, Canada, October 1993. 
[41] L. Cabrera, M. Elbuluk and D. Zinger, "Learning techniques to train neural networks as a state selector for inverter-fed induction machines", Proceedings of IEEE Power Electronics Specialists Conference (PESC), 1994.

[42] Luis Cabrera, M. Elbuluk " Tuning the Stator Resistance in Inverter-Fed Induction Machines Using Direct Self Control", IEEE 26 th Power Electronics Specialists Conference, (PESC'95), Atlanta, June 1995.
[43] M.Elbuluk and M.D. Kankam, "Motor Drive Technologies for the Power-By-Wire (PBW):Options, Trends and Tradeoffs, Part I: Power Electronic Converters and Devices," IEEE Aerospace and Electronics Magazine, Vol. 10, No. 11, November 1995, pp.37-41.

[44] M.Elbuluk and M.D. Kankam, "Motor Drive Technologies for the Power-By-Wire (PBW):Options, Trends and Tradeoffs, Part II: Motors and Controllers," IEEE Aerospace and Electronics Magazine, Vol. 10, No. 12 , November 1995, pp.31-36. 


\begin{tabular}{|c|c|c|c|}
\hline \multicolumn{3}{|c|}{ REPORT DOCUMENTATION PAGE } & $\begin{array}{l}\text { Form Approved } \\
\text { OMB No. 0704-0188 }\end{array}$ \\
\hline \multicolumn{4}{|c|}{$\begin{array}{l}\text { Public reporting burden for this collection of information is estimated to average } 1 \text { hour per response, including the time for reviewing instructions, searching existing data sources, } \\
\text { gathering and maintaining the data needed, and completing and reviewing the collection of information. Send comments regarding this burden estimate or any other aspect of this } \\
\text { collection of information, including suggestions for reducing this burden, to Washington Headquarters Services, Directorate for Information Operations and Reports, } 1215 \text { Jefferson } \\
\text { Davis Highway, Suite 1204, Arlington, VA 22202-4302, and to the Office of Mangagement and Budget, Paperwork Reduction Project (0704-0188), Washington, DC 20503. }\end{array}$} \\
\hline 1. AGENCY USE ONLY (Leave blank) & $\begin{array}{r}\text { 2. REPORT DATE } \\
\text { May } 1997\end{array}$ & \multicolumn{2}{|c|}{$\begin{array}{l}\text { 3. REPORT TYPE AND DATES COVERED } \\
\text { Technical Memorandum }\end{array}$} \\
\hline \multicolumn{3}{|c|}{$\begin{array}{l}\text { 4. TITLE AND SUBTITLE } \\
\text { Speed Sensorless Induction Motor Drives for Electrical Actuators: Schemes, } \\
\text { Trends and Tradeoffs }\end{array}$} & \multirow{2}{*}{$\begin{array}{l}\text { 5. FUNDING NUMBERS } \\
\text { WU-233-1A-1C }\end{array}$} \\
\hline \multicolumn{3}{|c|}{$\begin{array}{l}\text { 6. AUTHOR(S) } \\
\text { Malik E. Elbuluk and M. David Kankam }\end{array}$} & \\
\hline \multicolumn{3}{|c|}{$\begin{array}{l}\text { 7. PERFORMING ORGANIZATION NAME(S) AND ADDRESS(ES) } \\
\text { National Aeronautics and Space Administration } \\
\text { Lewis Research Center } \\
\text { Cleveland, Ohio } 44135-3191\end{array}$} & $\begin{array}{l}\text { 8. PERFORMING ORGANIZATION } \\
\text { REPORT NUMBER }\end{array}$ \\
\hline \multicolumn{3}{|c|}{$\begin{array}{l}\text { 9. SPONSORING/MONITORING AGENCY NAME(S) AND ADDRESS(ES) } \\
\text { National Aeronautics and Space Administration } \\
\text { Washington, DC 20546-0001 }\end{array}$} & $\begin{array}{l}\text { 10. SPONSORING/MONITORING } \\
\text { AGENCY REPORT NUMBER } \\
\text { NASA TM-107466 }\end{array}$ \\
\hline \multicolumn{4}{|c|}{$\begin{array}{l}\text { 11. SUPPLEMENTARY NOTES } \\
\text { Prepared for the National Aerospace and Electronics Conference cosponsored by IEEE, Wright-Patterson AFB, and AESS } \\
\text { Dayton, Ohio, July 14-18, 1997. Malik E. Elbuluk, University of Akron, Department of Electrical Engineering, Akron, } \\
\text { Ohio } 44325 \text { and Summer Faculty Fellow at NASA Lewis Research Center, and M. David Kankam, NASA Lewis Research } \\
\text { Center. Responsible person, M. David Kankam, organization code 5450, (216) } 433-6143 \text {. }\end{array}$} \\
\hline \multicolumn{3}{|c|}{$\begin{array}{l}\text { 12a. DISTRIBUTION/AVAILABILITY STATEMENT } \\
\text { Unclassified - Unlimited } \\
\text { Subject Categories } 07 \text { and } 08 \\
\text { This publication is available from the NASA Center for AeroSpace Information, (301) 621-0390. }\end{array}$} & 12b. DISTRIBUTION CODE \\
\hline \multicolumn{4}{|c|}{$\begin{array}{l}\text { For a decade, induction motor drive-based electrical actuators have been under investigation as potential replacement for the } \\
\text { conventional hydraulic and pneumatic actuators in aircraft. Advantages of electric actuator include lower weight and size, } \\
\text { reduced maintenance and operating costs, improved safety due to the elimination of hazardous fluids and high pressure hy- } \\
\text { draulic and pneumatic actuators, and increased efficiency. Recently, the emphasis of research on induction motor drives has } \\
\text { been on sensorless vector control which eliminates flux and speed sensors mounted on the motor. Also, the development of } \\
\text { effective speed and flux estimators has allowed good rotor flux-oriented (RFO) performance at all speeds except those close } \\
\text { to zero. Sensorless control has improved the motor performance, compared to the Volts/Hertz (or constant flux) controls. This } \\
\text { report evaluates documented schemes for speed sensorless drives, and discusses the trends and tradeoffs involved in selecting } \\
\text { a particular scheme. These schemes combine the attributes of the direct and indirect field-oriented control (FOC) or use } \\
\text { model adaptive reference systems (MRAS) with a speed-dependent current model for flux estimation which tracks the voltage } \\
\text { model-based flux estimator. Many factors are important in comparing the effectiveness of a speed sensorless scheme. Among } \\
\text { them are the wide speed range capability, motor parameter insensitivity and noise reduction. Although a number of schemes } \\
\text { have been proposed for solving the speed estimation, zero-speed FOC with robustness against parameter variations still re- } \\
\text { mains an area of research for speed sensorless control. }\end{array}$} \\
\hline \multirow{2}{*}{\multicolumn{3}{|c|}{$\begin{array}{l}\text { 14. SUBJECT TERMS } \\
\text { Aerospace; Electrical actuators; Sensorless induction motor drive; Speed identification } \\
\text { schemes; Model reference adaptive system; Aircraft; Launch vehicles }\end{array}$}} & $\begin{array}{c}\text { 15. NUMBER OF PAGES } \\
10\end{array}$ \\
\hline & & & $\begin{array}{r}\text { 16. PRICE CODE } \\
\text { A02 }\end{array}$ \\
\hline $\begin{array}{l}\text { 17. SECURITY CLASSIFICATION } \\
\text { OF REPORT } \\
\text { Unclassified }\end{array}$ & $\begin{array}{l}\text { 18. SECURITY CLASSIFICATION } \\
\text { OF THIS PAGE } \\
\text { Unclassified }\end{array}$ & $\begin{array}{l}\text { 19. SECURITY CLASSIFICATION } \\
\text { OF ABSTRACT } \\
\text { Unclassified }\end{array}$ & 20. LIMITATION OF ABSTRACT \\
\hline NSN 7540-01-280-5500 & & & \\
\hline
\end{tabular}

